\title{
Street Network Models and Measures for Every U.S. City, County, Urbanized Area, Census Tract, and Zillow-Defined Neighborhood
}

\section{Geoff Boeing}

School of Public Policy and Urban Affairs, Northeastern University, 360 Huntington Ave, 360Y RP, Boston, MA 02115, USA; g.boeing@northeastern.edu

Received: 28 December 2018; Accepted: 14 February 2019; Published: 1 March 2019

\begin{abstract}
OpenStreetMap provides a valuable crowd-sourced database of raw geospatial data for constructing models of urban street networks for scientific analysis. This paper reports results from a research project that collected raw street network data from OpenStreetMap using the Python-based OSMnx software for every U.S. city and town, county, urbanized area, census tract, and Zillow-defined neighborhood. It constructed nonplanar directed multigraphs for each and analyzed their structural and morphological characteristics. The resulting data repository contains over 110,000 processed, cleaned street network graphs (which in turn comprise over 55 million nodes and over 137 million edges) at various scales_comprehensively covering the entire U.S.- - archived as reusable open-source GraphML files, node/edge lists, and GIS shapefiles that can be immediately loaded and analyzed in standard tools such as ArcGIS, QGIS, NetworkX, graph-tool, igraph, or Gephi. The repository also contains measures of each network's metric and topological characteristics common in urban design, transportation planning, civil engineering, and network science. No other such dataset exists. These data offer researchers and practitioners a new ability to quickly and easily conduct graph-theoretic circulation network analysis anywhere in the U.S. using standard, free, open-source tools.
\end{abstract}

Keywords: street networks; graphs; network science; OpenStreetMap; urban planning; transportation

\section{Introduction}

Urban planners and transportation engineers have examined and modeled street networks for decades to explore household travel behavior, accessibility and equity, urban form and design patterns, connectivity, and centrality [1-26]. Complex networks such as street networks have also been explored from the perspective of statistical physics to assess structure and performance [27-44]. However, large volumes of cross-sectional street network data-in a format well-suited for graph-theoretic analysis-have often been difficult to come by, especially in an open-source, scalable, automatable way.

This paper presents a new data repository to address this gap. It describes a research project that downloaded raw OpenStreetMap street network data for the entire U.S., cleaned these data, then constructed graph-theoretic models of these data at multiple scales for fast and rigorous urban analysis. It then calculated dozens of metric and topological measures of each network, nationwide. These models and measures can save researchers weeks or months of ad hoc data collection and analysis. However, they are even more useful for urban planners and policymakers who often lack the technical capacity to write their own API scripts in custom query languages or implement their own network science algorithms to understand the built form and urban circulation.

This new data repository provides four significant value-additions for urban science and analytics. First, the repository contains graph-theoretic models in common reusable formats, immediately suited 
to spatial network analysis—unlike OpenStreetMap's raw geometry data downloads—out of the box. Second, these models all have meaningful spatial extents (municipalities, counties, urbanized areas, census tracts, and neighborhoods) that correspond to administrative boundaries and socio-spatial units in useful ways for urban analysis. Third, these graphs' topologies have all been substantially cleaned-up such that their nodes exclusively represent intersections and dead-ends, and their edges exclusively represent the street segments connecting them. Finally, this repository contains dozens of metric and topological measures calculated for each of the 110,000 study sites-no such database previously existed.

Building on recent work that developed the underlying data collection and modeling methodology [45], and presented initial empirical findings of geometric and topological trends in U.S. street network design [46], this paper documents a new undertaking of data collection, organization, and archiving to produce a newly-generated public repository of street network models and measures. This paper first briefly describes the background of street network models and data. Then it presents the methodology used to construct these street network graphs, analyze them, and produce the resulting models and indicators repositories. Finally, it concludes with a discussion of this work.

\section{Background}

\subsection{Street Network Models}

Graphs are mathematical models of networks [47-53]. A graph $G$ consists of a set of nodes $N$ connected to each other by a set of edges $E$. An edge connects one node to another, or one node to itself in the case of self-loops. In a directed graph, each edge points in a single direction from one node to another. For example, an edge $e_{u v}$ points from node $u$ to node $v$ but not reciprocally from $v$ to $u$. However, in an undirected graph, an edge points reciprocally in both directions between the nodes that it links. If a graph's edges intersect in two-dimensions exclusively at nodes, it is planar; otherwise, it is nonplanar [54-68].

In a primal representation of a street network, nodes represent intersections and dead-ends, while edges represent the street segments that link them [69]. Dual representations invert this topology such that nodes represent streets and edges represent their intersections [70]. This project only considers primal graphs, as they account for the full spatial and geographic characteristics of the street network [71,72]. Walkable networks allow undirected flow in both directions along an edge, but many (drivable) street networks include one-way streets that necessitate directed graphs for accurate modeling. Many street networks include self-loops as well as parallel edges (i.e., when two nodes are linked by multiple edges). A multigraph is a graph that allows for such parallel edges. This project models street networks as primal nonplanar directed multigraphs with possible self-loops.

\subsection{Street Network Data}

Street network data around the world come from disparate sources, resulting in inconsistencies in digitization, metadata, file formats, availability, and acquisition. Traditionally, most studies of U.S. street networks used the U.S. census bureau's TIGER/Line roads shapefiles (an official vector dataset of roads in the U.S.). While these shapefiles provide network geometry, they provide little information about topology. Street networks are embedded in geographic space, and thus are defined by both their spatial geometry and their topology: the connections and configurations of nodes and edges [73,74]. Thus, geographic shapefiles alone do not lend themselves immediately or easily to graph-theoretic network analysis. Moreover, TIGER/Line data contain substantial spatial inaccuracies and coarse-grained attribute data [75].

Online geographic information systems offer another source of data. However, "[w]hile proprietary systems such as Google Maps may be suitable for trip planning and similar applications, they cannot be used for most research and analytic purposes" [76] due to licensing terms, costs, access restrictions, and usage limitations. OpenStreetMap offers an alternative source of street network 
data [77]. It is an open-source, worldwide, collaborative mapping project. OpenStreetMap provides geospatial information about streets and intersections, along with attribute data about road types, names, and (sometimes) speeds, widths, and numbers of lanes. However, its data cannot by default be automatically extracted into a graph-theoretic object for network analysis [78]. Furthermore, the network topology must be substantially cleaned to correctly represent nodes exclusively as intersections and dead-ends. Prior to this wider project, no tools or data repositories enabled the automatic, at-scale, configurable acquisition of OpenStreetMap data and construction of graph-theoretic data objects for analysis.

\section{Methods}

Given this background and motivation, this project originally developed a new open-source Python-based software toolkit called OSMnx [45]. OSMnx can download data from OpenStreetMap using configurable user queries, then construct a nonplanar, directed multigraph, and finally clean the topology [79]. Python was chosen to develop this tool for three reasons. First, Python is one of the most popular programming languages in the world, giving it a broad audience. Second, Python offers particularly simple and straightforward syntax, making it easy for newcomers to learn and lowering the scientific barriers to entry. Third, it has become a standard language for data science research and practice, with an extensive ecosystem of related packages for scientific, network, and geospatial analysis. Finally, other similar tools in this space include dodgr (an R tool for distance calculations on weighted directed graphs), shp2graph (an $\mathrm{R}$ tool for converting spatial networks into igraph objects) [80], pandana (a Python tool for network accessibility queries) [81], the Urban Network Analysis Toolbox plugin for ArcGIS and Rhino [82], and GISF2E (a Python tool that processes shapefiles into edge lists) [78]. However, none of these offer the end-to-end capabilities of OSMnx to download network data directly, build models, clean the topology, and conduct statistical analyses and simulations.

To construct this data repository, this project used OSMnx to download network data and construct graphs for the drivable street networks of every U.S. city/town, county, urbanized area, census tract, and Zillow-defined neighborhood (Zillow is a large online real estate database company that defines neighborhood boundaries in many cities and towns). It saved these graphs as shapefiles, GraphML files (a standard, open-source format for graph serialization), and node/edge lists. Finally, it analyzed these networks to assess the geometric, topological, and morphological characteristics of U.S. street networks and how they reflect various urban planning eras, transportation technologies, economic conditions, and design paradigms. These study sites are presented in Figure 1.

\subsection{Graph Production}

To produce the data in the repository, we loaded five publicly-available input datasets defining these study sites into OSMnx version 0.8.1 in May 2018:

1. U.S. census bureau 2017 places shapefiles for all 50 states. Census "places" comprise cities, towns, equivalent entities, and census-designated places. For this project, we discard the latter (small unincorporated communities) to retain and analyze every city and town $(N=19,678)$ in the U.S.

2. U.S. census bureau 2017 nationwide counties $(N=3233)$ shapefile.

3. U.S. census bureau 2017 nationwide urban areas shapefile. Census "urban areas" comprise urbanized areas and urban clusters. For this project, we discard the latter (small agglomerations) to retain and analyze every urbanized area $(N=497)$ in the U.S. [83].

4. U.S. census bureau 2017 nationwide census tracts $(N=74,133)$ shapefile.

5. Zillow's neighborhood boundaries $(N=17,037)$ shapefiles, per-state, March 2018 release [84-86]. Zillow is a prominent real estate database company, and their boundaries dataset covers large U.S. cities. 

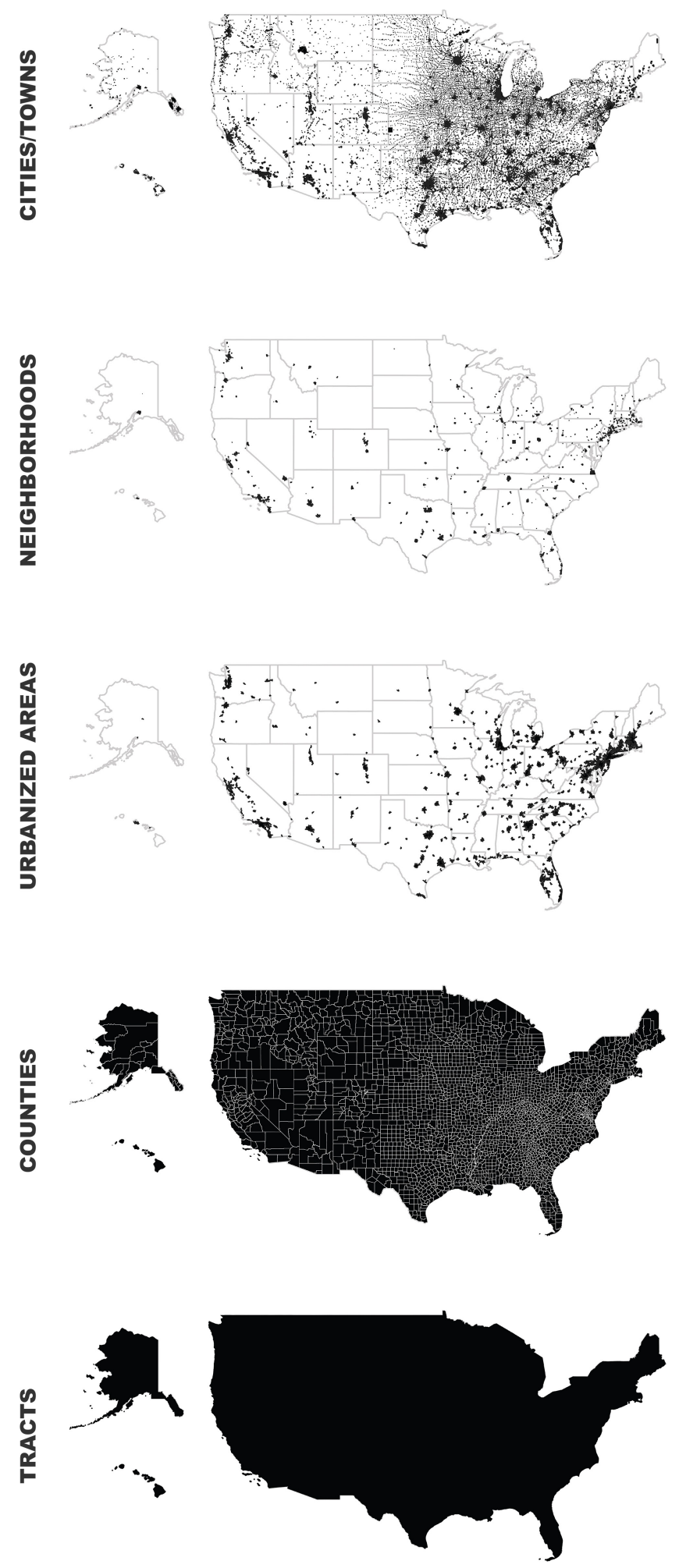

Figure 1. The dataset's study sites' coverage (black): 19,678 cities/towns, 17,037 Zillow-defined neighborhoods, 497 urbanized areas, 3233 counties, and 74,133 census tracts. Alaska and Hawaii not to scale.

One at a time, for each city, county, urbanized area, tract, and neighborhood boundary defined in the above shapefiles, we downloaded the drivable public street network within its boundaries from 
OpenStreetMap using OSMnx. To acquire these raw data, OSMnx buffers each boundary polygon by $500 \mathrm{~m}$ then downloads the streets within this geometry, filtering them based on attribute data. It then constructs a nonplanar directed multigraph. In the case of one-way streets, a directed edge is added from the origin node to the destination node. However, for bidirectional streets, reciprocal directed edges are added in each direction between the two nodes.

Next, OSMnx cleans the graph's topology to retain nodes only at intersections and dead-ends (detailed below). However, the full edge spatial geometry and length are retained in the cleaned graph. Then, it calculates node degrees and node types before truncating the graph to the original boundary polygon. This buffer/truncate workflow attenuates perimeter effects [87] and guarantees that true intersections are not incorrectly considered pseudo-nodes or dead-ends if an incident edge links to a node outside the boundary polygon. The final graph may be strongly connected, weakly connected, or neither. If it is not connected, OSMnx returns all connected components as a single graph object.

To clean the graph's topology, OSMnx only retains nodes that represent the junction of multiple streets, as depicted in Figure 2. First, it identifies all non-intersection pseudo-nodes (i.e., all those that simply form an expansion graph). Next, it removes these pseudo-nodes while maintaining the true spatial geometry and attribute data of the street segment between the true intersection nodes. In strict mode, OSMnx considers two-way "intersections" to be topologically identical to a single street that bends around a curve. Conversely, to retain these intersections when the incident edges have different OpenStreetMap IDs, we can use OSMnx's non-strict mode. This cleaning step is critical to this dataset, providing additional value beyond extraction of data from OpenStreetMap itself by producing models more suitable to urban design/morphology and transportation analysis by representing intersections/dead-ends as nodes and linear blocks' sides as edges.
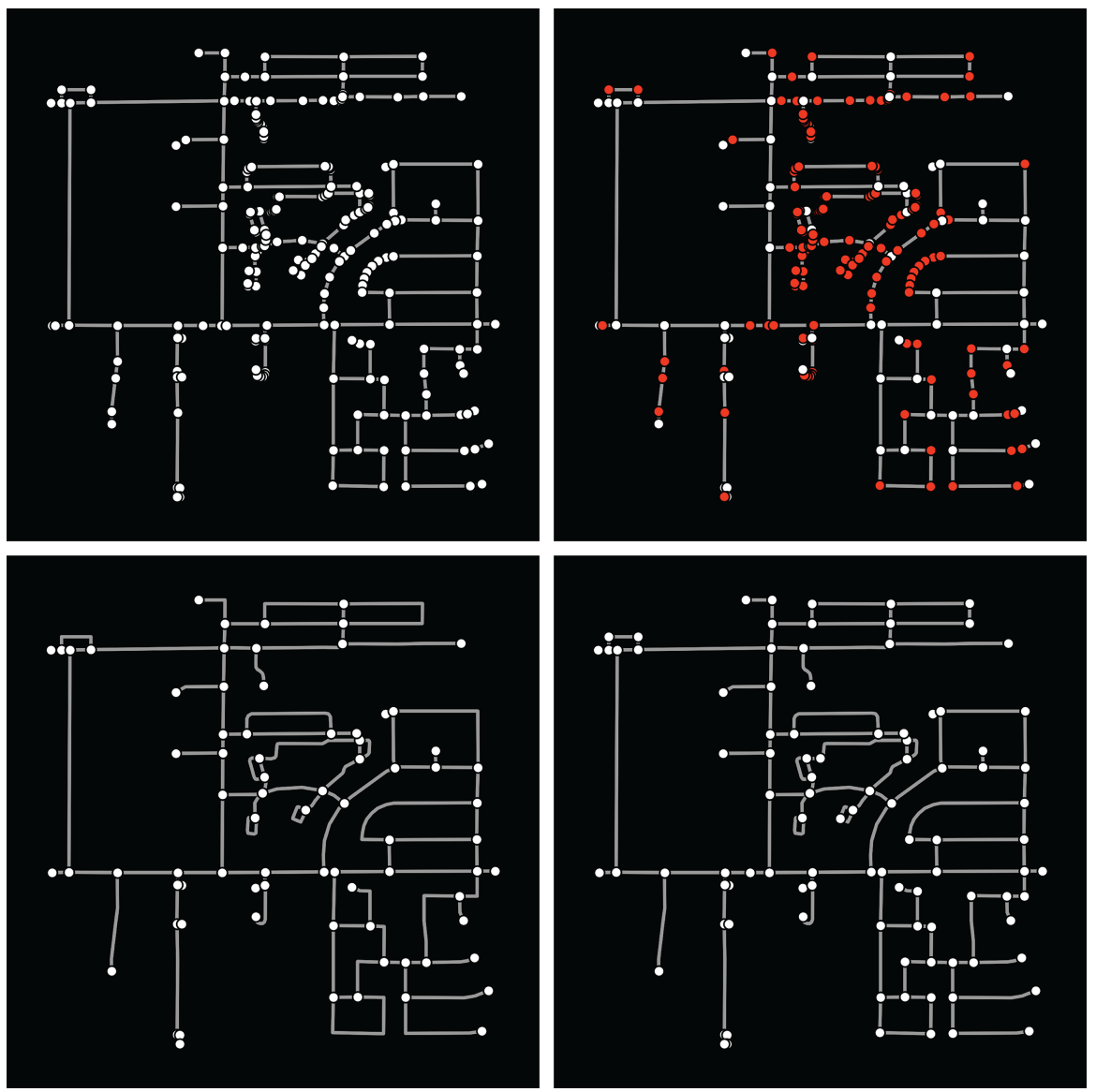

Figure 2. OSMnx street network topology cleaning. (Top-left) original graph (nodes in white, edges in gray). (Top-right) original graph (strict-mode pseudo-nodes highlighted in red). (Bottom-left) graph simplified in strict mode. (Bottom-right) graph simplified in non-strict mode. 
Once we have constructed and cleaned the graph, we use OSMnx to save it to disk as node/edge lists (formatted as comma-separated values), as ESRI shapefiles to work with in GIS software, and as a GraphML file (an open-source, standard format for serializing graphs) to work with in common network analysis software packages such as NetworkX, Gephi, graph-tool, or igraph [88-90]. OSMnx's saved shapefiles include separate node and edge layers. When saving shapefiles, OSMnx simplifies the network to an undirected representation but preserves one-way origin-destination directionality as edge attributes for subsequent GIS-based routing applications.

\subsection{Graph Analysis}

Finally, for this repository we calculate several metric and topological measures of each of these networks, common in the urban design, transportation planning, and network science disciplines. These measures include each network's area $\left(\mathrm{km}^{2}\right)$, mean average neighborhood degree, mean average weighted neighborhood degree, average circuity, average clustering coefficient, average weighted clustering coefficient, average degree centrality, edge density $\left(\mathrm{m} / \mathrm{km}^{2}\right)$, average edge length $(\mathrm{m})$, total edge length $(\mathrm{m})$, count of intersections, intersection density (per $\mathrm{km}^{2}$ ), count of dead-ends, proportion of nodes that are dead-ends, count of three-way intersections, proportion of nodes that are three-way intersections, count of four-way intersections, proportion of nodes that are four-way intersections, average node degree $\bar{k}$, count of edges $m$, count of nodes $n$, node density (per $\mathrm{km}^{2}$ ), maximum and minimum node PageRank (a measure of node importance based on the structure of incoming edges), proportion of edges that self-loop, street density $\left(\mathrm{m} / \mathrm{km}^{2}\right)$, average street segment length $(\mathrm{m})$, total street length $(\mathrm{m})$, count of street segments, and average number of streets per node.

These measures are described in Table 1 and extended technical definitions and mathematical derivations can be found in $[3,16,32,45,48,51,73,91-106]$. Note that we distinguish between "edges" and physical "streets" in certain instances to not double-count bidirectional streets with reciprocal edges pointing in both directions. Dozens of additional graph-theoretic measures can be easily calculated by loading these GraphML files into OSMnx [45].

Table 1. Descriptions of network measures in the dataset.

\begin{tabular}{ll}
\hline Measure & Definition \\
\hline area & $\begin{array}{l}\text { land area of cities, counties, and urbanized areas; gross area of } \\
\text { neighborhoods }\left(\mathrm{km}^{2}\right) \text { ) }\end{array}$ \\
\hline mean avg neighborhood degree & mean of all average neighborhood degrees in network \\
\hline avg weighted neighborhood degree & $\begin{array}{l}\text { mean degree of nodes in the neighborhood of each node, weighted } \\
\text { by edge length }\end{array}$ \\
\hline $\begin{array}{l}\text { mean avg weighted neighborhood } \\
\text { degree }\end{array}$ & mean of all weighted average neighborhood degrees in network \\
\hline avg circuity & $\begin{array}{l}\text { total edge length divided by sum of great circle distances between } \\
\text { the nodes incident to each edge }\end{array}$ \\
\hline avg clustering coefficient & $\begin{array}{l}\text { mean of clustering coefficients (extent to which node's } \\
\text { neighborhood forms a complete graph) of all nodes }\end{array}$ \\
\hline avg weighted clustering coefficient & mean of weighted clustering coefficients of all nodes \\
\hline avg degree centrality & mean of all degree centralities in network \\
\hline avg edge length & mean edge length in network (m) \\
\hline total edge length & sum of edge lengths in network (m) \\
\hline edge density & total edge length divided by area \\
\hline intersection count & number of intersections in network \\
\hline intersection density & intersection count divided by area \\
\hline dead-end count & number of dead-end nodes in the network \\
\hline
\end{tabular}


Table 1. Cont.

\begin{tabular}{|c|c|}
\hline Measure & Definition \\
\hline dead-end proportion & proportion of nodes that are dead-ends \\
\hline three-way intersection count & number of three-way intersection in the network \\
\hline three-way intersection proportion & proportion of nodes that are three-way intersections \\
\hline four-way intersection count & number of four-way intersection in the network \\
\hline four-way intersection proportion & proportion of nodes that are four-way intersections \\
\hline$n$ & number of nodes in network \\
\hline$m$ & number of edges in network \\
\hline avg node degree $(\bar{k})$ & $\begin{array}{l}\text { mean number of inbound and outbound edges incident to the } \\
\text { nodes }\end{array}$ \\
\hline node density & $n$ divided by area in square kilometers \\
\hline maximum PageRank & $\begin{array}{l}\text { highest PageRank (ranking of nodes based on structure of } \\
\text { incoming edges) value of any node in the graph }\end{array}$ \\
\hline minimum PageRank & lowest PageRank value of any node in the graph \\
\hline self-loop proportion & $\begin{array}{l}\text { proportion of edges that have a single incident node (i.e., edge } e_{u v} \\
\text { where } u=v \text { ) }\end{array}$ \\
\hline street density & total street length divided by area in square kilometers \\
\hline avg street segment length & mean edge length in undirected representation of network (m) \\
\hline total street length & sum of edge lengths in undirected representation of network $(\mathrm{m})$ \\
\hline count of street segments & number of edges in undirected representation of network \\
\hline avg streets per node & $\begin{array}{l}\text { mean number of physical streets that emanate from each node } \\
\text { (intersections and dead-ends) }\end{array}$ \\
\hline
\end{tabular}

\subsection{Data and Code Availability}

These data are freely available online at the Harvard Dataverse at https: / / dataverse.harvard. edu/osmnx-street-networks. This repository includes the graphs of the street networks for every U.S. city, county, urbanized area, census tract, and Zillow neighborhood as a GraphML file, node/edge shapefiles, and node/edge lists. These files can be loaded into any standard GIS software or network analysis package. It also contains the analytical measures for every street network. The datasets are available in the following two repositories:

1. Boeing, G. U.S. Street Network Shapefiles, Node/Edge Lists, and GraphML Files. Harvard Dataverse, v2. https:// doi.org/10.7910/DVN/CUWWYJ (2018)

2. Boeing, G. U.S. Street Network Analytic Measures. Harvard Dataverse, v2. https://doi.org/10. 7910/DVN/F5UNSK (2018)

All the code to download and analyze these street networks with OSMnx (version 0.8.1) is open-source and available on GitHub at https://github.com/gboeing/dataverse-street-networks. The OSMnx software itself is also open-source and freely available for download and installation from GitHub (https: / / github.com/gboeing/osmnx), the PyPI package repository (https:/ / pypi.org/ project/OSMnx/), and the Anaconda package repository (https:/ / anaconda.org/conda-forge/osmnx).

\section{Discussion}

This paper described a new urban science data repository constructed from raw OpenStreetMap data that provides four significant value-additions. First, the repository contains graph-theoretic models in common reusable formats, immediately more useful than typical raw geometry data downloads out of the box. Second, these models all have meaningful spatial extents (municipalities, 
counties, urbanized areas, census tracts, and neighborhoods) that correspond to administrative boundaries or social units for urban analysis and simulation. Third, these graphs have substantially cleaned-up topologies such that nodes exclusively represent intersections and dead-ends and edges represent the street segments connecting them. Fourth, this repository contains dozens of metric and topological measures calculated for each graph-no such database previously existed. These measures can be used to analyze the urban fabric's texture and walkability (via intersection density, node/edge density, and average street segment length), connectivity (via average number of streets per node and circuity), and network resilience and importance (via centrality measures and PageRank).

In total, this data repository contains over 110,000 street networks which in turn collectively comprise over 55 million nodes and over 137 million edges. While these data fill a gap in helping researchers quickly ramp-up graph-theoretic street network analyses in the U.S. without having to spend weeks developing their own ad hoc data collection, modeling, and analysis workflows, they fill a larger gap in opening up these scientific modes of urban analysis to planners and policymakers without the individual technical or institutional capacity to do so otherwise. Yet to use these data accordingly, they must reasonably model the real world. Validation of these data can be considered from two perspectives. The first considers how faithfully the OpenStreetMap data represent the real-world street network. The second considers how faithfully the repository's graphs in turn represent the OpenStreetMap street network.

Regarding the former perspective, various authors have explored this subject in detail [76,107-114]. OpenStreetMap's road data quality is generally quite high-for example, Garmin consumer GPS devices can use OpenStreetMap roads data for navigation. Although data coverage varies worldwide, it is generally good when compared to corresponding estimates from the CIA World Factbook. In the US, OpenStreetMap imported the 2005 TIGER/Line roads in 2007 as a foundational data source. Since then, numerous corrections and improvements have been made. More importantly, many additions have been made beyond what TIGER/Line captures, including richer attribute data describing the characteristics of features and finer-grained codes for classifying streets. Of course, much of these data are crowd-sourced and user-generated, and errors thus occasionally exist. However, the data are validated and vetted by the OpenStreetMap community, resulting in high quality overall. Most relevant to this project's study area, the U.S. network is essentially complete on OpenStreetMap [76].

Regarding the latter perspective, we comprehensively tested the final dataset's quality, adapting the methodologies of $[76,78]$ against three reference datasets: the TIGER/Line roads, Google Earth satellite imagery, and the OpenStreetMap raw source data. The first step uses QGIS to compare these data spatially against the TIGER/Line roads shapefile in a random sample of 100 cities to identify any edges appearing in one of these datasets but missing in the other. Discrepancies were then checked one at a time to ensure they correctly matched the OpenStreetMap source and secondarily against Google Earth satellite imagery for real-world verification. Finally, tests are performed on each graph to ensure they can be loaded, analyzed, and routed. The validation confirmed that this project's algorithms reconstructed the OSM data properly with nodes exclusively at intersections and dead-ends.

Comprehensive documentation for using OSMnx is available at https:/ / osmnx.readthedocs.org and tutorials, examples, and demonstrations are available at https:/ /github.com/gboeing/osmnxexamples. To reuse this dataset, researchers can install OSMnx according to the installation instructions in the documentation. Then, they can load the GraphML files using OSMnx's load_graphml function. The graphs may be similarly loaded in NetworkX, graph-tool, igraph, and other similar network analysis tools. To load these graphs with Gephi, first load the GraphML file in OSMnx, re-export it using OSMnx's save_graphml function with argument gephi=True (to add additional customization for Gephi compatibility), then open the exported file in Gephi. The shapefiles may be loaded in standard fashion in any GIS software, such as QGIS, ArcGIS, or geopandas. 
Funding: This research received no specific external funding.

Acknowledgments: The author wishes to thank Paul Waddell, Robert Cervero, David O'Sullivan, Elizabeth Macdonald, and Luis Bettencourt for their helpful comments and suggestions during the development of this project.

Conflicts of Interest: The author declares no conflict of interest.

\section{References}

1. Levinson, D. Network Structure and City Size. PLoS ONE 2012, 7, e29721. [CrossRef] [PubMed]

2. Cervero, R.; Kockelman, K. Travel Demand and the 3 Ds: Density, Diversity, and Design. Transp. Res. Part D Transp. Environ. 1997, 2, 199-219. [CrossRef]

3. Ewing, R.; Cervero, R. Travel and the Built Environment: A Meta-Analysis. J. Am. Plan. Assoc. 2010, 76, 265-294. [CrossRef]

4. Talen, E. Measuring Urbanism: Issues in Smart Growth Research. J. Urban Des. 2003, 8, 195-215. [CrossRef]

5. Grannis, R. The Importance of Trivial Streets: Residential Streets and Residential Segregation. Am. J. Sociol. 1998, 103, 1530-1564. [CrossRef]

6. Southworth, M.; Ben-Joseph, E. Streets and the Shaping of Towns and Cities; McGraw-Hill: New York, NY, USA, 1997.

7. Marshall, W.; Garrick, N. Street network types and road safety: A study of 24 California cities. Urban Des. Int. 2010, 15, 133-147. [CrossRef]

8. Marshall, W.; Piatkowski, D.; Garrick, N. Community design, street networks, and public health. J. Transp. Health 2014, 1, 326-340. [CrossRef]

9. Karimi, K. A configurational approach to analytical urban design: "Space syntax" methodology. Urban Des. Int. 2012, 17, 297-318. [CrossRef]

10. Horner, M.W.; Murray, A.T. Excess commuting and the modifiable areal unit problem. Urban Stud. 2002, 39, 131-139. [CrossRef]

11. Dessemontet, P.; Kaufmann, V.; Jemelin, C. Switzerland as a Single Metropolitan Area? A Study of its Commuting Network. Urban Stud. 2010, 47, 2785-2802. [CrossRef]

12. Lee, J.; Sohn, K. Identifying the Impact on Land Prices of Replacing At-grade or Elevated Railways with Underground Subways in the Seoul Metropolitan Area. Urban Stud. 2014, 51, 44-62. [CrossRef]

13. Porta, S.; Romice, O.; Maxwell, J.A.; Russell, P.; Baird, D. Alterations in scale: Patterns of change in main street networks across time and space. Urban Stud. 2014, 51, 3383-3400. [CrossRef]

14. Porta, S.; Latora, V.; Strano, E. Networks in Urban Design: Six Years of Research in Multiple Centrality Assessment. In Network Science: Complexity in Nature and Technology; Estrada, E., Fox, M., Higham, D.J., Oppo, G.L., Eds.; Springer: London, UK, 2010; pp. 107-129.

15. Porta, S.; Latora, V.; Wang, F.; Rueda, S.; Strano, E.; Scellato, S.; Cardillo, A.; Belli, E.; Càrdenas, F.; Cormenzana, B.; et al. Street Centrality and the Location of Economic Activities in Barcelona. Urban Stud. 2012, 49, 1471-1488. [CrossRef]

16. Hajrasouliha, A.; Yin, L. The impact of street network connectivity on pedestrian volume. Urban Stud. 2015, 52, 2483-2497. [CrossRef]

17. Parthasarathi, P.; Levinson, D.; Hochmair, H. Network Structure and Travel Time Perception. PLoS ONE 2013, 8, e77718. [CrossRef] [PubMed]

18. Parthasarathi, P.; Hochmair, H.; Levinson, D. Street network structure and household activity spaces. Urban Stud. 2015, 52, 1090-1112. [CrossRef]

19. Knight, P.L.; Marshall, W.E. The metrics of street network connectivity: Their inconsistencies. J. Urban. Int. Res. Placemak. Urban Sustain. 2015, 8, 241-259. [CrossRef]

20. Xiao, Y.; Webster, C.; Orford, S. Identifying house price effects of changes in urban street configuration: An empirical study in Nanjing, China. Urban Stud. 2016, 53, 112-131. [CrossRef]

21. Zhong, C.; Arisona, S.M.; Huang, X.; Batty, M.; Schmitt, G. Detecting the dynamics of urban structure through spatial network analysis. Int. J. Geograph. Inf. Sci. 2014, 28, 2178-2199. [CrossRef]

22. Zhong, C.; Schläpfer, M.; Arisona, S.M.; Batty, M.; Ratti, C.; Schmitt, G. Revealing centrality in the spatial structure of cities from human activity patterns. Urban Stud. 2017, 54, 437-455. [CrossRef] 
23. Barthelemy, M. From paths to blocks: New measures for street patterns. Environ. Plan. B Urban Anal. City Sci. 2017, 44, 256-271. [CrossRef]

24. Barrington-Leigh, C.; Millard-Ball, A. A century of sprawl in the United States. Proc. Natl. Acad. Sci. USA 2015, 112, 8244-8249. [CrossRef] [PubMed]

25. Boeing, G. Measuring the Complexity of Urban Form and Design. Urban Des. Int. 2018, 23, $281-292$. [CrossRef]

26. Rose-Redwood, R.; Bigon, L. Gridded Worlds: An Urban Anthology; Springer: Cham, Switzerland, 2018.

27. Barthelemy, M. Betweenness centrality in large complex networks. Eur. Phys. J. B Condens. Matter Complex Syst. 2004, 38, 163-168. [CrossRef]

28. Barthelemy, M.; Flammini, A. Modeling Urban Street Patterns. Phys. Rev. Lett. 2008, 100, 138702. [CrossRef] [PubMed]

29. Barthelemy, M. Morphogenesis of Spatial Networks; Springer: New York, NY, USA, 2017.

30. Barthelemy, M.; Bordin, P.; Berestycki, H.; Gribaudi, M. Self-organization versus top-down planning in the evolution of a city. Sci. Rep. 2013, 3, 2153. [CrossRef] [PubMed]

31. Albert, R.; Barabási, A.L. Statistical mechanics of complex networks. Rev. Mod. Phys. 2002, 74, 47. [CrossRef]

32. Costa, L.D.F.; Rodrigues, F.A.; Travieso, G.; Villas Boas, P.R. Characterization of complex networks: A survey of measurements. Adv. Phys. 2007, 56, 167-242. [CrossRef]

33. Dorogovtsev, S.; Mendes, J. Evolution of networks. Adv. Phys. 2002, 51, 1079-1187. [CrossRef]

34. Crucitti, P.; Latora, V.; Porta, S. Centrality measures in spatial networks of urban streets. Phys. Rev. E 2006, 73, 036125. [CrossRef] [PubMed]

35. Crucitti, P.; Latora, V.; Porta, S. Centrality in networks of urban streets. Chaos Interdiscip. J. Nonlinear Sci. 2006, 16, 015113. [CrossRef] [PubMed]

36. Buhl, J.; Gautrais, J.; Reeves, N.; Solé, R.V.; Valverde, S.; Kuntz, P.; Theraulaz, G. Topological patterns in street networks of self-organized urban settlements. Eur. Phys. J. B Condens. Matter Complex Syst. 2006, 49, 513-522. [CrossRef]

37. Chan, S.H.Y.; Donner, R.V.; Lämmer, S. Urban road networks-Spatial networks with universal geometric features? Eur. Phys. J. B 2011, 84, 563-577. [CrossRef]

38. Strano, E.; Nicosia, V.; Latora, V.; Porta, S.; Barthelemy, M. Elementary processes governing the evolution of road networks. Sci. Rep. 2012, 2, 296. [CrossRef] [PubMed]

39. Strano, E.; Viana, M.; da Fontoura Costa, L.; Cardillo, A.; Porta, S.; Latora, V. Urban Street Networks, a Comparative Analysis of Ten European Cities. Environ. Plan. B Plan. Des. 2013, 40, 1071-1086. [CrossRef]

40. Louf, R.; Barthelemy, M. A typology of street patterns. J. R. Soc. Interface 2014, 11, 20140924. [CrossRef] [PubMed]

41. Gudmundsson, A.; Mohajeri, N. Entropy and order in urban street networks. Sci. Rep. 2013, 3, 3324. [CrossRef] [PubMed]

42. Mohajeri, N.; Gudmundsson, A. The Evolution and Complexity of Urban Street Networks: Urban Street Networks. Geograph. Anal. 2014, 46, 345-367. [CrossRef]

43. Li, W.; Hu, D.; Liu, Y. An improved measuring method for the information entropy of network topology. Trans. GIS 2018, 22, 1632-1648. [CrossRef]

44. Courtat, T.; Gloaguen, C.; Douady, S. Mathematics and morphogenesis of cities: A geometrical approach. Phys. Rev. E 2011, 83, 036106. [CrossRef] [PubMed]

45. Boeing, G. OSMnx: New Methods for Acquiring, Constructing, Analyzing, and Visualizing Complex Street Networks. Comput. Environ. Urban Syst. 2017, 65, 126-139. [CrossRef]

46. Boeing, G. A Multi-Scale Analysis of 27,000 Urban Street Networks: Every US City, Town, Urbanized Area, and Zillow Neighborhood. Environ. Plan. B Urban Anal. City Sci. 2018, doi:10.1177/2399808318784595. [CrossRef]

47. Newman, M.E.J. The Structure and Function of Complex Networks. SIAM Rev. 2003, 45, 167-256. [CrossRef]

48. Newman, M.E.J. Networks: An Introduction; Oxford University Press: Oxford, UK, 2010.

49. Trudeau, R.J. Introduction to Graph Theory, 2nd ed.; Dover Publications: New York, NY, USA, 1994.

50. Vespignani, A. Twenty years of network science. Nature 2018. [CrossRef] [PubMed]

51. Brandes, U.; Erlebach, T. (Eds.) Network Analysis: Methodological Foundations; Number 3418 in Lecture Notes in Computer Science; Springer: Berlin, Germany, 2005. 
52. Gastner, M.T.; Newman, M.E.J. The spatial structure of networks. Eur. Phys. J. B Condens. Matter Complex Syst. 2006, 49, 247-252. [CrossRef]

53. Marshall, S.; Gil, J.; Kropf, K.; Tomko, M.; Figueiredo, L. Street Network Studies: From Networks to Models and their Representations. Netw. Spat. Econ. 2018. [CrossRef]

54. Aldous, D.J. Routed Planar Networks. Electron. J. Graph Theory Appl. 2016, 4, 42-59. [CrossRef]

55. Boeing, G. Planarity and Street Network Representation in Urban Form Analysis. Environ. Plan. B Urban Anal. City Sci. 2018. [CrossRef]

56. Boyer, J.M. Subgraph Homeomorphism via the Edge Addition Planarity Algorithm. J. Graph Algorithms Appl. 2012, 16, 381-410. [CrossRef]

57. Cardillo, A.; Scellato, S.; Latora, V.; Porta, S. Structural properties of planar graphs of urban street patterns. Phys. Rev. E 2006, 73, 066107. [CrossRef] [PubMed]

58. Chimani, M.; Gutwenger, C. Non-planar core reduction of graphs. Discret. Math. 2009, 309, 1838-1855. [CrossRef]

59. Chimani, M.; Hliněný, P.; Mutzel, P. Vertex insertion approximates the crossing number of apex graphs. Eur. J. Comb. 2012, 33, 326-335. [CrossRef]

60. Eppstein, D.; Goodrich, M.T. Studying (Non-planar) Road Networks Through an Algorithmic Lens. In Proceedings of the 16th ACM SIGSPATIAL International Conference on Advances in Geographic Information Systems, GIS '08, Irvine, CA, USA, 5-7 November 2008; p. 16.

61. Fohl, P.; Curtin, K.M.; Goodchild, M.F.; Church, R.L. A non-planar, lane-based navigable data model for ITS. In Proceedings of the Seventh International Symposium on Spatial Data Handling, Delft, The Netherlands, 12-16 August 1996; pp. 17-29.

62. Hopcroft, J.; Tarjan, R. Efficient Planarity Testing. J. ACM 1974, 21, 549-568. [CrossRef]

63. Liebers, A. Planarizing graphs-A survey and annotated bibliography. J. Graph Algorithms Appl. 2001, 5, 257-330. [CrossRef]

64. Masucci, A.P.; Smith, D.; Crooks, A.; Batty, M. Random planar graphs and the London street network. Eur. Phys. J. B Condens. Matter Complex Syst. 2009, 71, 259-271. [CrossRef]

65. Székely, L.A. A successful concept for measuring non-planarity of graphs: The crossing number. Discret. Math. 2004, 276, 331-352. [CrossRef]

66. Viana, M.P.; Strano, E.; Bordin, P.; Barthelemy, M. The simplicity of planar networks. Sci. Rep. 2013, 3, 3495. [CrossRef] [PubMed]

67. Law, S. Defining Street-based Local Area and measuring its effect on house price using a hedonic price approach. Cities 2017, 60, 166-179. [CrossRef]

68. Dill, J. Measuring network connectivity for bicycling and walking. In Proceedings of the Transportation Research Board 83rd Annual Meeting, Washington, DC, USA, 11-15 January 2004.

69. Porta, S.; Crucitti, P.; Latora, V. The network analysis of urban streets: A primal approach. Environ. Plan. B Plan. Des. 2006, 33, 705-725. [CrossRef]

70. Porta, S.; Crucitti, P.; Latora, V. The network analysis of urban streets: A dual approach. Phys. A Stat. Mech. Appl. 2006, 369, 853-866. [CrossRef]

71. Ratti, C. Space syntax: Some inconsistencies. Environ. Plan. B Plan. Des. 2004, 31, 487-499. [CrossRef]

72. Batty, M. Network geography: Relations, interactions, scaling and spatial processes in GIS. In Re-Presenting GIS; Unwin, D.J., Fisher, P., Eds.; John Wiley \& Sons: Chichester, UK, 2005; pp. 149-170.

73. Barthelemy, M. Spatial networks. Phys. Rep. 2011, 499, 1-101. [CrossRef]

74. O'Sullivan, D. Spatial Network Analysis. In Handbook of Regional Science; Fischer, M.M., Nijkamp, P., Eds.; Springer: Berlin, Germany, 2014; pp. 1253-1273.

75. Frizzelle, B.; Evenson, K.; Rodriguez, D.; Laraia, B. The importance of accurate road data for spatial applications in public health: Customizing a road network. Int. J. Health Geogr. 2009, 8, 24. [CrossRef] [PubMed]

76. Barrington-Leigh, C.; Millard-Ball, A. The world's user-generated road map is more than $80 \%$ complete. PLoS ONE 2017, 12, e0180698. [CrossRef] [PubMed]

77. Jokar Arsanjani, J.; Zipf, A.; Mooney, P.; Helbich, M. (Eds.) OpenStreetMap in GIScience; Lecture Notes in Geoinformation and Cartography; Springer: Cham, Switzerland, 2015.

78. Karduni, A.; Kermanshah, A.; Derrible, S. A protocol to convert spatial polyline data to network formats and applications to world urban road networks. Sci. Data 2016, 3, 160046. [CrossRef] [PubMed] 
79. Boeing, G. Methods and Measures for Analyzing Complex Street Networks and Urban Form. Ph.D. Thesis, University of California, Berkeley, CA, USA, 2017.

80. Lu, B.; Sun, H.; Harris, P.; Xu, M.; Charlton, M. Shp2graph: Tools to Convert a Spatial Network into an Igraph Graph in R. ISPRS Int. J. Geo-Inf. 2018, 7, 293. [CrossRef]

81. Foti, F. Behavioral Framework for Measuring Walkability and its Impact on Home Values and Residential Location Choices. Ph.D. Thesis, University of California, Berkeley, CA, USA, 2014.

82. Sevtsuk, A.; Mekonnen, M. Urban network analysis. A new toolbox for ArcGIS. Revue Internationale de Géomatique 2012, 22, 287-305. [CrossRef]

83. U.S. Census Bureau. 2010 Census Urban and Rural Classification and Urban Area Criteria. 2010. Available online: https:/ / www.census.gov/geo/reference/ua/urban-rural-2010.html (accessed on 2 January 2019).

84. Schernthanner, H.; Asche, H.; Gonschorek, J.; Scheele, L. Spatial Modeling and Geovisualization of Rental Prices for Real Estate Portals. In Computational Science and Its Applications-ICCSA 2016; Gervasi, O., Murgante, B., Misra, S., Rocha, A.M.A.C., Torre, C.M., Taniar, D., Apduhan, B.O., Stankova, E., Wang, S., Eds.; Number 9788 in Lecture Notes in Computer Science; Springer: Cham, Switzerland, 2016; pp. 120-133.

85. Besbris, M.; Faber, J.W.; Rich, P.; Sharkey, P. Effect of neighborhood stigma on economic transactions. Proc. Natl. Acad. Sci. USA 2015, 112, 4994-4998. [CrossRef] [PubMed]

86. Albrecht, J.; Abramovitz, M. Indicator Analysis for Unpacking Poverty in New York City; Technical Report; CUNY: New York, NY, USA, 2014.

87. Gil, J. Street network analysis "edge effects": Examining the sensitivity of centrality measures to boundary conditions. Environ. Plan. B Urban Anal. City Sci. 2017, 44, 819-836. [CrossRef]

88. ESRI. Shapefile Technical Description; White Paper J-7855; Environmental Systems Research Institute: Redlands, CA, USA, 1998.

89. Brandes, U.; Eiglsperger, M.; Herman, I.; Himsolt, M.; Marshall, M.S. GraphML Progress Report: Structural Layer Proposal. In Graph Drawing; Goos, G., Hartmanis, J., van Leeuwen, J., Mutzel, P., Jünger, M., Leipert, S., Eds.; Springer: Berlin/Heidelberg, Germany, 2002; Volume 2265, pp. 501-512.

90. Hagberg, A.; Conway, D. Hacking Social Networks Using the Python Programming Language. Presented at the Sunbelt 2010: International Network for Social Network Analysis, Riva del Garda, Italy, 29 June-4 July 2010.

91. Giacomin, D.J.; Levinson, D.M. Road network circuity in metropolitan areas. Environ. Plan. B Plan. Des. 2015, 42, 1040-1053. [CrossRef]

92. Boeing, G. The Morphology and Circuity of Walkable and Drivable Street Networks. In The Mathematics of Urban Morphology; D'Acci, L., Ed.; Birkhäuser: Basel, Switzerland, 2019.

93. Boeing, G. Urban Spatial Order: Street Network Orientation, Configuration, and Entropy. arXiv 2019, arXiv:1808.00600.

94. Beineke, L.W.; Oellermann, O.R.; Pippert, R.E. The Average Connectivity of a Graph. Discret. Math. 2002, 252,31-45. [CrossRef]

95. Jiang, B.; Claramunt, C. Integration of space syntax into GIS: New perspectives for urban morphology. Trans. GIS 2002, 6, 295-309. [CrossRef]

96. Jiang, B.; Claramunt, C. Topological Analysis of Urban Street Networks. Environ. Plan. B Plan. Des. 2004, 31, 151-162. [CrossRef]

97. Jiang, B. A Topological Pattern of Urban Street Networks: Universality and Peculiarity. Phys. A Stat. Mech. Appl. 2007, 384, 647-655. [CrossRef]

98. Mandloi, D.; Thill, J.C. Object-Oriented Data Modeling of an Indoor/Outdoor Urban Transportation Network and Route Planning Analysis. In Geospatial Analysis and Modelling of Urban Structure and Dynamics; Jiang, B., Yao, X., Eds.; Springer: Dordrecht, The Netherlands, 2010; Volume 99, pp. 197-220.

99. Brin, S.; Page, L. The anatomy of a large-scale hypertextual web search engine. Comput. Netw. ISDN Syst. 1998, 30, 107-117.

100. Agryzkov, T.; Oliver, J.L.; Tortosa, L.; Vicent, J.F. An algorithm for ranking the nodes of an urban network based on the concept of PageRank vector. Appl. Math. Comput. 2012, 219, 2186-2193. [CrossRef]

101. Chin, W.C.B.; Wen, T.H. Geographically Modified PageRank Algorithms: Identifying the Spatial Concentration of Human Movement in a Geospatial Network. PLoS ONE 2015, 10, e0139509. [CrossRef] [PubMed] 
102. Dankelmann, P.; Oellermann, O.R. Bounds on the average connectivity of a graph. Discret. Appl. Math. 2003, 129, 305-318. [CrossRef]

103. Cranmer, S.J.; Leifeld, P.; McClurg, S.D.; Rolfe, M. Navigating the range of statistical tools for inferential network analysis. Am. J. Polit. Sci. 2017, 61, 237-251. [CrossRef]

104. Opsahl, T.; Panzarasa, P. Clustering in weighted networks. Soc. Netw. 2009, 31, 155-163. [CrossRef]

105. Gleich, D.F. PageRank Beyond the Web. SIAM Rev. 2015, 57, 321-363. [CrossRef]

106. Huang, X.; Zhao, Y.; Ma, C.; Yang, J.; Ye, X.; Zhang, C. TrajGraph: A Graph-Based Visual Analytics Approach to Studying Urban Network Centralities Using Taxi Trajectory Data. IEEE Trans. Vis. Comput. Graph. 2016, 22, 160-169. [CrossRef] [PubMed]

107. Barron, C.; Neis, P.; Zipf, A. A Comprehensive Framework for Intrinsic OpenStreetMap Quality Analysis. Trans. GIS 2014, 18, 877-895. [CrossRef]

108. Basiri, A.; Jackson, M.; Amirian, P.; Pourabdollah, A.; Sester, M.; Winstanley, A.; Moore, T.; Zhang, L. Quality assessment of OpenStreetMap data using trajectory mining. Geospat. Inf. Sci. 2016, 19, 56-68. [CrossRef]

109. Corcoran, P.; Mooney, P.; Bertolotto, M. Analysing the growth of OpenStreetMap networks. Spat. Stat. 2013, 3, 21-32. [CrossRef]

110. Girres, J.F.; Touya, G. Quality Assessment of the French OpenStreetMap Dataset. Trans. GIS 2010, 14, 435-459. [CrossRef]

111. Haklay, M. How Good is Volunteered Geographical Information? A Comparative Study of OpenStreetMap and Ordnance Survey Datasets. Environ. Plan. B Plan. Des. 2010, 37, 682-703. [CrossRef]

112. Maron, M. How complete is OpenStreetMap? Mapbox, 19 November 2015. Available online: https: / / www.mapbox.com/blog/how-complete-is-openstreetmap/ (accessed on 2 January 2019).

113. Neis, P.; Zielstra, D.; Zipf, A. The Street Network Evolution of Crowdsourced Maps: OpenStreetMap in Germany 2007-2011. Future Internet 2011, 4, 1-21. [CrossRef]

114. Zielstra, D.; Hochmair, H.H.; Neis, P. Assessing the Effect of Data Imports on the Completeness of OpenStreetMap-A United States Case Study. Trans. GIS 2013, 17, 315-334. [CrossRef]

(C) 2019 by the authors. Licensee MDPI, Basel, Switzerland. This article is an open access article distributed under the terms and conditions of the Creative Commons Attribution (CC BY) license (http:/ / creativecommons.org/licenses/by/4.0/). 